This item was submitted to Loughborough's Research Repository by the author.

Items in Figshare are protected by copyright, with all rights reserved, unless otherwise indicated.

\title{
Moving forward with membership categorization analysis: Methods for systematic analysis
}

PLEASE CITE THE PUBLISHED VERSION

https://doi.org/10.1177/1461445612441534

PUBLISHER

SAGE $\odot$ The Author

VERSION

AM (Accepted Manuscript)

\section{PUBLISHER STATEMENT}

This work is made available according to the conditions of the Creative Commons Attribution-NonCommercialNoDerivatives 4.0 International (CC BY-NC-ND 4.0) licence. Full details of this licence are available at: https://creativecommons.org/licenses/by-nc-nd/4.0/

\section{LICENCE}

CC BY-NC-ND 4.0

\section{REPOSITORY RECORD}

Stokoe, Elizabeth. 2019. "Moving Forward with Membership Categorization Analysis: Methods for Systematic Analysis". figshare. https://hdl.handle.net/2134/26625. 
PAPER FOR DISCOURSE STUDIES

Moving forward with membership categorization analysis: Methods for systematic analysis

Elizabeth Stokoe

Department of Social Sciences

Loughborough University

Loughborough

LE11 3TU

UK

Tel: $+44(0) 1509223360$

Fax: +44(0)1509 223944

e.h.stokoe@lboro.ac.uk

Short title: Moving forward with membership categorization analysis

Published in Discourse Studies, 14(3) 277-303, June 2012

DOI: $10.1177 / 1461445612441534$ 


\section{BIOGRAPHY}

Elizabeth Stokoe is Professor of Social Interaction in the Department of Social Sciences at Loughborough University, UK. Her current research interests are in conversation analysis, membership categorization, and social interaction in various ordinary and institutional settings, including neighbour mediation, police interrogation, role-play and simulated interaction. She is the co-author of Discourse and Identity (with Bethan Benwell, Edinburgh University Press, 2006) and co-editor of Conversation and Gender (with Susan Speer, Cambridge University Press, 2011). 


\begin{abstract}
This paper has four aims. First, it will consider explicitly, and polemically, the hierarchical relationship between conversation analysis (CA) and membership categorization analysis (MCA). Whilst the CA 'juggernaut' flourishes, the MCA 'milk float' is in danger of being run off the road. For MCA to survive either as a separate discipline, or within $C A$ as a focus equivalent to other 'generic orders of conversation', I suggest it must generate new types of systematic studies and reveal fundamental categorial practices. With such a goal in mind, the second aim of the paper is to provide a set of clear analytic steps and procedures for conducting MCA, which are grounded in basic categorial and sequential concerns. Third, the paper aims to demonstrate how order can be found in the intuitively 'messy' discourse phenomenon of membership categories, and how to approach their analysis systematically as a robust feature of particular action-oriented environments. Through the exemplar analyses, the final aim of the paper is to promote MCA as a method for interrogating culture, reality, and society, without recourse to its reputed 'wild and promiscuous' analytic approach.
\end{abstract}

KEYWORDS: membership categorization analysis, conversation analysis, action, sequence, gender categories. 


\section{INTRODUCTION}

Conversation analysis (henceforth 'CA') and membership categorization analysis (henceforth 'MCA') are two ethnomethodological methods for analyzing interactional and textual practices. Whilst both are rooted in Sacks's (1992) ground-breaking Lectures on

Conversation, the two methods have had somewhat divergent trajectories. There are hundreds of highly cited CA journal articles and books, but far fewer MCA publications. There are numerous CA textbooks, undergraduate and graduate courses, and workshops and conferences, but only a handful of MCA equivalents. Whilst there are, of course, many studies that deploy aspects of Sacks's work on membership categories, in CA and related disciplines (e.g., discursive psychology: see Antaki \& Widdicombe, 1998; Edwards, 1998), there are far fewer studies that claim a specific or 'pure' MCA framework. Relatively speaking, CA is the 'juggernaut' to MCA's 'milk float'. Because of this, MCA is in danger of dying. Indeed, one might argue that it has never been properly born. Its status relative to CA suggests that it is unlikely to develop fully and survive as a distinct discipline. This is especially the case since a focus on membership categorization is currently enjoying something of a renaissance within "the discipline" of CA itself (Schegloff, 2005: 457; see Hansen, 2005; Schegloff, 2007a; Whitehead, 2009). As Wilkinson and Kitzinger (2008: 565) have noted, "the application of CA work on person reference and membership categorization" is one of the "most vibrant areas" in contemporary CA. Whilst CA is 'upgraded', MCA is 'derogated' (Carlin, 2010: 257). The juggernaut may run the milk float off the road.

This paper is not necessarily a manifesto for the 'MCA party'. I am ambivalent with regards to the maintenance of distinct methods versus the study of categories being subsumed into CA, as one of its 'generic orders of conversation' (alongside person reference practices 
within 'the word selection problem': Schegloff, 2007b). MCA gives researchers with a primary interest in categorial or 'topical' (e.g., gender, sexuality, ethnicity, identity), rather than sequential issues, an empirically tractable method for studying those issues, as members', rather than analysts', categories (see Speer \& Stokoe, 2011). To date, however, the two methods have attended to related but consequentially different aspects of discourse practice. Whereas CA “...specifies the normative structuring and logics of particular courses of social action and their organization into systems through which participants manage turntaking, repair, and other systemic dimensions of interaction" (Heritage, 2005: 104, emphasis added), MCA focuses on "members' methodical practices in describing the world, and displaying their understanding of the world and of the commonsense routine workings of society" (Fitzgerald, Housley \& Butler, 2009: 47, emphasis added). Whilst conversation analysts have criticized membership categorization analysis for failing to engage with sequential matters (Schegloff, 2007a), membership categorization analysts have suggested that conversation analysts set "categorization relevances at zero" (Watson, 1997: 50; see also Carlin, 2010). These analytic foci are, unsurprisingly, cashed out in different sorts of empirical studies. CA works principally ${ }^{1}$ across large conversational data corpora to identify, cumulatively, robust structural patterns in turn-taking, repair, sequence organization, and action formation. In contrast, MCA mainly produces case studies of distinct interactional and textual settings, focusing on turn-generated 'identities-for-interaction', morality, culture and other categorial matters (e.g., Eglin \& Hester, 1999; Housley \& Fitzgerald, 2007; Plunkett, 2009; Summerfield \& McHoul, 2005).

So, despite claims that categories are "relevant for the doing of some activity" (Sacks, 1992: 597) and that "both the sequential and categorizational aspects of social interaction inform each other" (Hester \& Eglin, 1997: 2; see also Silverman, 1998), “the two 'branches' of Sacks's work have developed largely in isolation from one another" (Plunkett, 2009: 24). 
And so, because of "the uneasy relations [between MCA and CA] ... analysis that explicitly treats both categorization and sequential aspects of talk is hardly done" (Hansen, 2005: 67, emphasis added). One reason why categories and sequences have rarely been studied concurrently is to do with the 'capturability' of categorial phenomenon (Stokoe, 2009a; 2010a). It is interesting that whilst the body of CA work has revealed "order at all points" (Sacks, 1992: 484), in contrast to Chomsky’s (e.g., 1957) assumptions about the 'disorderliness of real talk' (i.e., 'performance'; hence his focus on 'competence'), discourse and conversation analysts have made comparable comments about the 'disorderliness of categories' as problem for their systematic analysis:

We cannot 'simply go into the field and observe how, when, where, and with whom people talk with others about [identity] groups ... Finding data ... would amount to a search for the proverbial needle in the haystack (Van Dijk, 1987: 18; 119)

Because we cannot know in advance when a person will explicitly invoke a ... category, there is no way to plan data collection of them ... collections ... in all likelihood, would not be instances of the same interactional phenomenon (Pomerantz \& Mandelbaum, 2005: 154)

And so conversation analysts have argued that "establishing the mechanisms by which a specific identity is made relevant and consequential in any particular episode of interaction has remained ... elusive" (Raymond \& Heritage, 2006: 677).

This paper challenges such arguments, and makes a case for the systematic analysis of membership categories and related phenomena. It takes up Sacks's (often idiosyncratic) observations about membership categories and shows how to track categorial concerns in the 
same way that CA has pursued sequential practices. In so doing, the paper will provide 'how to' examples for the systematic analysis of membership categories. I am not arguing that one should treat sequential or categorial concerns as "analytic alternatives" (Carlin, 2010: 258). But a reinvigorated focus on MCA will protect and maintain some of its most exciting aspects, such as the analysis of constructed reality; of culture, identity and morality; of inference and meaning; of the analysis of interactional and textual materials, and its ethnomethodological spirit. If MCA is to survive - if it is to be respected; if it is to address Schegloff's (2007a: 477) concerns about embracing "the rest of the field of which it is presumptively a part and what has been learned in it - I mean, conversation analysis" - then a clear approach to the identification of robust, systematic categorial practices is now due.

\section{DOING MEMBERSHIP CATEGORIZATION ANALYSIS}

As noted earlier, there is an absence of 'how to do' MCA in the broader ethnomethodological literature. To the best of my knowledge, only one textbook exists (Lepper, 2000); although a small number of other books, articles and chapters include descriptions of categorization methodology (e.g., Baker; 2000; Hester \& Eglin, 1997; Silverman, 1998; 2001). Key MCA publications make visible aspects of the method-in-use (e.g., Hester \& Eglin, 1997; Housley \& Fitzgerald, 2009; Jayyusi, 1991; Lee, 1984; Wowk, 1984; Watson, 1978). Schegloff’s (2007a) tutorial also explains clearly Sacks's treatment of categories. In Sidnell's (2010, pp. 29-35) recent CA textbook, he lists a number of 'suggestions' about CA's analytic steps. These include looking for "patterns across data samples" (e.g., collecting instances of particular turn-initial phenomena), "patterns within the data" (e.g., silence after a particular type of turn), "selecting formulations" (e.g., how a particular person, object or event is described), and "selecting formats" (e.g., distinguishing between different methods for 
accomplishing action). Additionally, he lists a number of 'keys' that analysts can use to track through and define instances of CA phenomena (e.g., self-repair, transition relevance places, silence, etc.).

In a similar vein, I offer five guiding principles for doing MCA. These principles are gleaned partly from reading the key articles listed above and recovering their (sometimes implicit) analytic procedures, and partly in what I see now, post-hoc, as the clearest way to begin and proceed with a categorization study. It may be the case that one approaches an MCA study with a particular category in mind: I became interested in MCA in the first instance because I was interested in exploring 'gender' and its relevance to interaction (in contrast to sociolinguistic studies of gender differences in interactional style: e.g., Stokoe, 1998). The empirical examples I present later in this paper are all examples of gender categories, but, of course, any category can be pursued in the same way. Below, then, are the five guiding principles followed by a glossary of ten key concepts derived from Sacks's and subsequent MCA work.

1. Collect data across different sorts of domestic and institutional settings; collect both interactional and textual materials depending on the focus of the study. Data collection maybe purposive (e.g., gathering together instances of particular categories in use because of an a priori interest in that category) or unmotivated (e.g., noticing a category's use and pursuing it within and across multiple discourse sites).

2. Build collections of explicit mentions of categories (e.g., man, human, boy-racer, anarchist, teacher, Australian, pianist, prostitute, lesbian, etc.); membership categorization devices (e.g., 'occupation', 'parties to a crime', 'stage of life', 'sex', 'family', etc.) and category-resonant descriptions (e.g., the descriptions 'she's eightynine years old' and 'don't be so testosterony' do not mention categories explicitly but 
are attributes that "convey the sense ... of being deployed as categories" Schegloff, 2007a: 480).

3. Locate the sequential position of each categorial instance with the ongoing interaction, or within the text.

4. Analyze the design and action orientation of the turn or text in which the category, device or resonant description appears.

5. Look for evidence that and how recipients orient to the category, device or resonant description; for the interactional consequences of a category's use; for co-occurring component features of categorial formulations, and for the way speakers within and between turns build and resist categorizations.

Furthermore, as 'keys' into the data, here are ten key concepts and of membership categorization:

1. Membership categorization device: This refers to the apparatus through which categories are understood to 'belong' to a collective category (e.g., the categories 'mommy' and 'baby' are heard to belong to the MCD 'family'). Categories may belong to myriad MCDs (e.g., 'baby' can belong to the MCDs 'stage of life', or 'terms of endearment'), via various rules of application.

2. Category-bound activities: Activities that are, in situ, linked to categories, such as "Why are men [category] so reluctant to go to the doctors [activity]?"

3. Category-tied predicates: A category's characteristics, such as "this mother [category] cares [predicate] tremendously for her baby".

4. Standardized relational pairs: Pairs of categories that carry duties and moral obligations in relation to the other, such as 'parent-child'; 'teacher-pupil'; 'neighbour- 
neighbour'.

5. Duplicative organization: Categories that work in a unit or 'teamlike' way, having specific obligations to each other, such as 'centre-forward', 'goalkeeper' and 'defender' in a 'football team'; 'mother', 'father', 'aunt', 'sister' and 'son' in the same 'family'.

6. Positioned categories: Some collections of categories occupy a hierarchical relationship (e.g., 'baby', 'teenager', 'adult'), such that an 'adult' can be accused of behaving like a 'teenager', and so on.

7. Category-activity 'puzzles': People can do particular actions by putting together (un)expected combinations such as "Killer Nuns!"; jokes are often built this way (e.g., 'women drivers'); gendering is often marked this way (e.g., 'male nurse'); social change becomes visible as such associations diminish, are replaced or deleted (Sacks, 1979).

8. The economy rule: A single category may be sufficient to describe a person, such as in Silverman's (2001) example of the newspaper headline: 'Father and Daughter in Snow Ordeal'.

9. The consistency rule: If two or more categories are used next to each other, like 'father' and 'daughter' in 'Father and Daughter in Snow Ordeal', and both belong to a standard collection or MCD (e.g. family), then hear the people referred to as members of the same family: as each other's father and daughter (Silverman, 2001).

10. Categorization 'maxims': As consequence of these rules of application, Sacks (1992: 221 ; 259) derived the hearer's maxim for duplicatively organized categories ("if two or more categories are used to categorize two or more members of some population, and those categories can be heard as categories from the same collection, then: hear them that way") and the viewer's maxim for category-bound activities ("if a Member 
sees a category-bound activity being done, then, if one sees it being done by a member of a category to which the activity is bound, see it that way").

That activities and predicates are category-bound - and that categories can be positioned hierarchically and organized duplicatively or in SRPs - can become a resource for action. Thus people can complain about 'absent activities' (e.g., if a neighbour [category] plays loud music at night [activity]; if a lecturer does not fulfil their obligations to a student [two categories in a standardized relational pair]). However, it is important to note that categories, activities and predicates do not 'go together' in a decontextualized way, independent of any given stretch of discourse. Rather, their 'going together' "is achieved and is to be found in the local specifics of categorization as an activity" (Hester \& Eglin, 1997: 46). In other words, such 'going together' "cannot simply be asserted on the analyst's authority" (Schegloff, 1992: xlii), separate from sequentially-grounded warrants for such claims.

Debates about CA and MCA, then, are related to debates between conversation analysts and other (mainly critical) discourse analysts who purportedly make assertions about their data 'without warrant'. A persistent issue for MCA is how far it is possible, for any category, for analysts to 'assert' what the relevant activities, predicates, and so on are, such that the analysis does not become 'wild and promiscuous' (see Schegloff, 1992; 2007a). That is, how far can one claim the relevance of categorial phenomena that are not formulated explicitly and unambiguously by speakers? And what is left to analyse if everything is made explicit? The issue remains rather fuzzy because, according to Sacks, categories are 'inference-rich'. This means that categories store "a great deal of the knowledge that members of a society have about the society" (Sacks, 1992: 40-41). A particular 'woman' may also be correctly categorized as a 'mother', 'lady', 'wife' or 'daughter', but each category carries a different set of category bound activities, predicates, or rights and 
obligations that are expectable for an incumbent of that category to perform or possess . Categories and their inferential upshots can be implied, but not overtly stated, by mentioning some category-incumbent features. For instance, Sacks discusses how a suicidal man uses descriptions such as, 'I was a hair stylist at one time, I did some fashions now and then, things like that' to imply for himself possible incumbency of a homosexual identity (this was in 1960s California). He claims that "there are ways of introducing a piece of information and testing out whether it will be acceptable, which don't involve saying it" (p. 47).

As Edwards (p.c.) argues, it is not the job of analysts to be more specific about categorization practices, or, more generally, about designedly ambiguous descriptions and actions, than members themselves are. The fact that we cannot be definitive about relevant categories and inferences is what gives language practices their defeasibility: that Sacks's suicidal man was 'homosexual' remains provisional and, crucially, deniable (Benwell \& Stokoe, 2006). For example, 'flirting' is an action that may be readily recast as 'friendly' in response to an accusation thereof, or as a face-saving alternative if flirting is not reciprocated. However, the appeal (and danger) of MCA is to try to unpack what is apparently unsaid by members and produce an analysis of their subtle categorization work. And there is another issue. As mentioned earlier, my interest in MCA arose from dissatisfaction with sociolinguistic studies of gender and language, in which 'gender' is used unproblematically as an analysts' category and correlated with speech styles. I adopted Schegloff's (1991) criteria for relevance to approach my analyses of gender as a participants' category for interaction. However, Schegloff (2005) himself appears to rely on analysts' categories in his study of a teenage girl's 'whining'; that is, the girl, Virginia, can be seen to be whining because it is a 'childish' attenuation of 'crying' and she is a 'child' (p.469). Although Virginia is categorized as a child by her mother and brother (which she resists!), Schegloff's specific claims about her 'whining' rest on his categorization of her. 
Debates about analytic principles will inevitably continue. The aim of this paper is to demonstrate a usable method for MCA, rather than commit to particular 'side' in such debates. In the illustrative analyses that follow, I focus on speakers' explicit and largely unambiguous uses of categories, across numerous datasets. Yet the 'category-generated features' (Jayyusi, 1984) that get tied to them; the actions they accomplish; the local and cultural meanings they acquire, maintain or transform, and the overarching patterns in their use, are what I aim to identify and unpack.

\section{DATA}

The data for this paper come from a variety of mainly British domestic, institutional and online settings. Some was collected as part of an ESRC-funded research project ${ }^{2}$ investigating neighbour disputes across escalating contexts of legally-powerful settings (including mediation, antisocial behaviour council services, and the police). Other extracts are drawn from radio broadcasts, web forums, television programmes, and conversations between friends. Where appropriate, all participants consented to have their talk recorded and anonymized for research purposes. The data (except the American television data) were transcribed according to Jefferson's (2004) system for conversation analysis; for video material, still images ${ }^{3}$ of key turns in an extract are presented.

\footnotetext{
ANALYSIS

The three analytic sections that follow each examine category work in particular actionoriented environments. The first looks at categorization in advice-giving sequences; the second focuses on identifying component features of categorial practices in account-giving,
} 
and the third shows how speakers can 'go categorial' in question-answer 'adjacency pairs'.

Each section, therefore, attends to categorial, sequential and action-formation concerns.

However, the focus on the 'categorial' also affords insights into commonsense notions about the meaning of those categories under investigation. MCA unpacks people's 'reality-analysis' (Hester \& Francis, 1997); that is, how categories are stipulated, how membership in a category is accountable, and, particularly, how speakers proffer their category work as common, cultural knowledge. I want to show that such proffering - and categorization work in general - is produced endogenously by participants, rather than by the 'wild and promiscuous' style of analysis for which MCA has been criticized.

\section{(1) A categorial basis for advice-giving}

The first extract comes from the American sitcom 'Friends'. In this episode, one of the characters, Chandler, has been on a first date. He is telling his friends Joey, Monica, Ross and Phoebe about the date while they are at their local coffee shop.

\section{Extract 1: Friends Season 1: 'The One with the Evil Orthodontist}

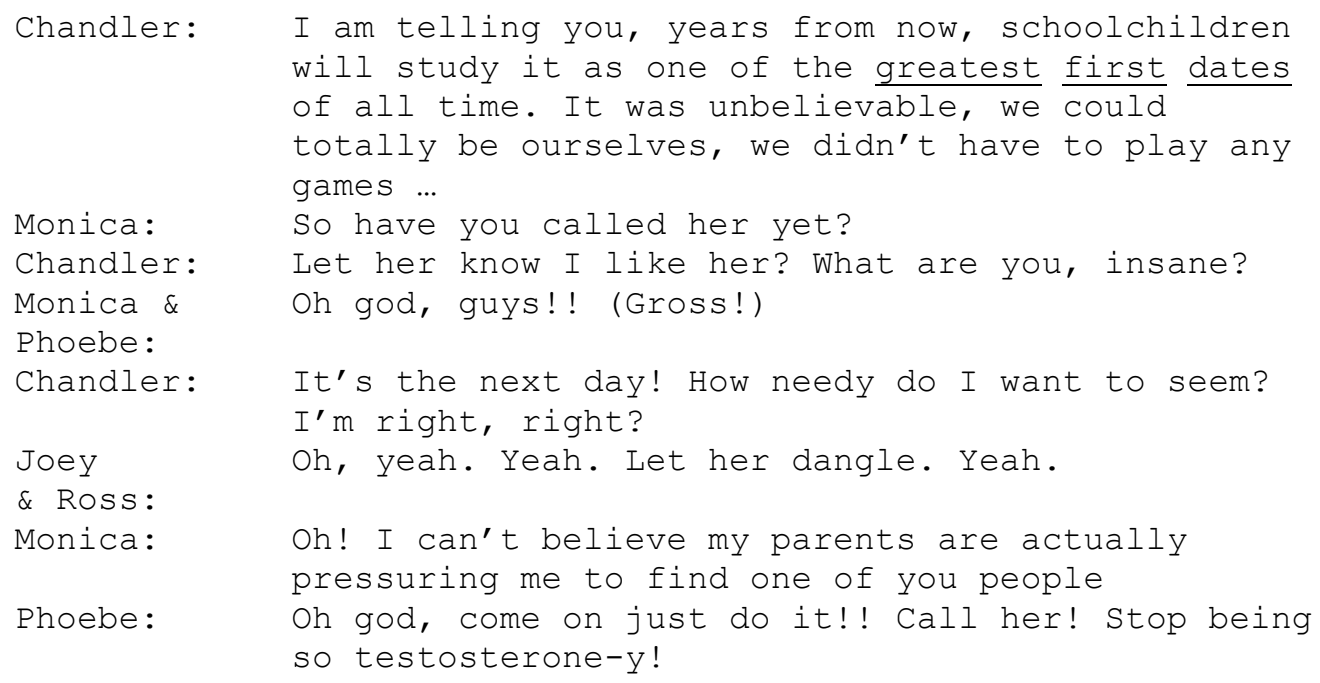




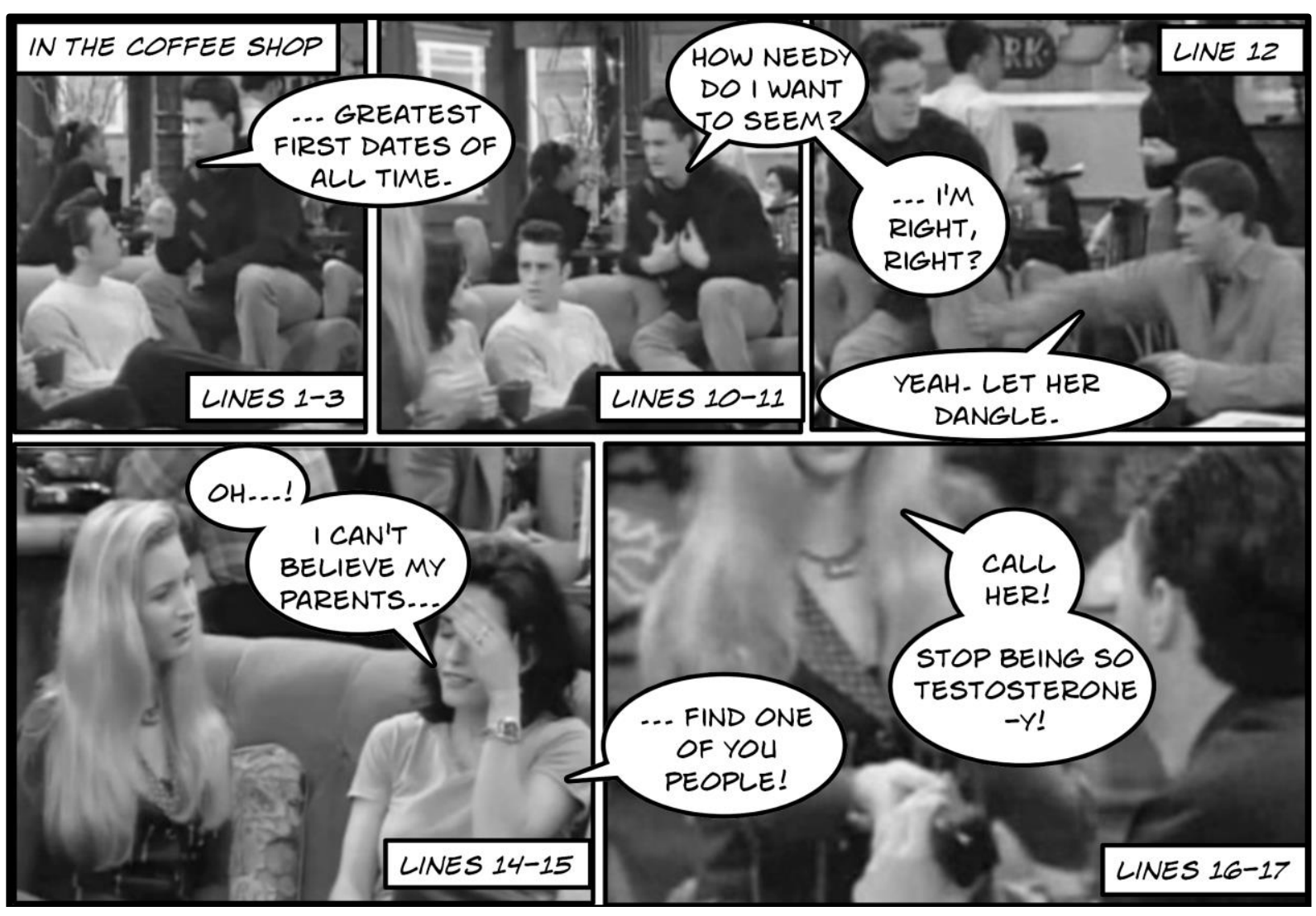

In response to Chandler's recounting of his 'greatest first date' with a woman, Monica asks him whether or not he has "called her yet". In response, Chandler's implicit 'no' is embedded in an account for why he has not called: he does not want to let the woman know he likes her by calling too soon and seeming "needy" (lines 7-10). The humour in this sequence emerges in part from the contrast between Chandler's characterization of the date in which there was no "game playing" (lines 4-5), and his subsequent dating strategy which includes hiding how he feels about her. In response, the friends (via the scriptwriters) partition themselves into two groups according to the membership categorization device ('MCD') 'sex'. While the men, Joey and Ross, ratify Chandler's suggested course of action, it is treated as, and rejected by the women, Monica and Phoebe, as a gendered course of action.

So, at lines 14-15, Monica states that she “can’t believe my parents are actually pressuring me to find one of you people!" Despite her use of the gender-neutral category 
'people', in the situated context of its production, and taking into account the 'perceptually available categories' (Jayyusi, 1984) by which the participants are physically arranged, 'people' becomes 'heterosexual men', while 'me' is 'me as a woman'. These are, as Jackson (2011: 31) describes, types of reference that are "hearably gendered, without the speaker's categorical membership being explicitly linguistically produced". Phoebe's response further specifies 'people' as gendered, as she treats the activities under discussion - calling someone immediately after a date, not letting someone know you like them, not looking needy, letting women dangle - as tied to being 'testosterony'. To not be 'testosterony' is to 'call her' (line 17). As a 'predicate' of the category 'male', 'testosterony' is a 'category-resonant description' (Schegloff, 2007a). This is not to say that this category-predicate combination is always tied to the category male, in some objective way. Rather, such category-generated features emerge in actual stretches of talk, with regard to particular states of affairs or narrative accounts.

In the next extract, which comes from a conversation between friends who are talking together as they prepare for a night out, similar categorial formulations occur.

\section{Extract 2: VH-1}

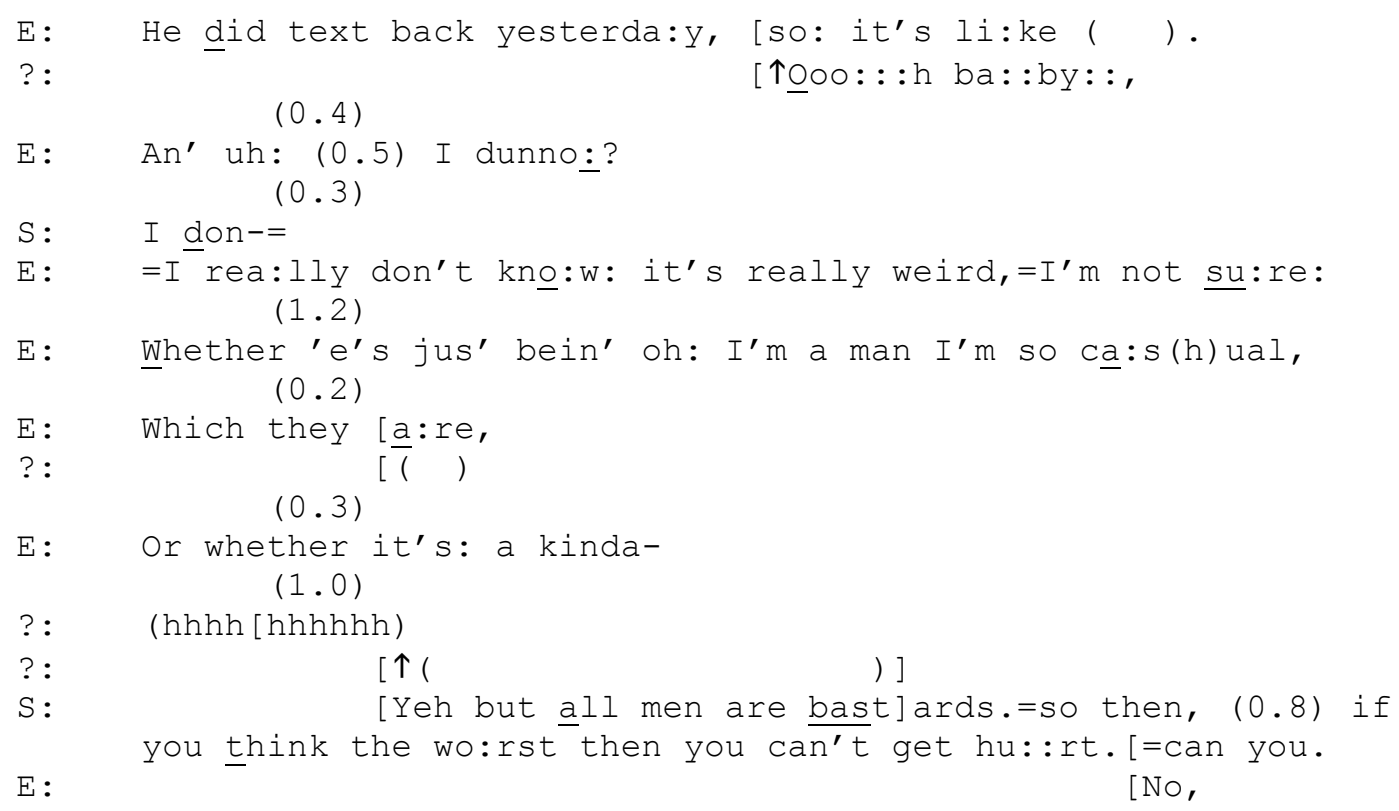


Despite Extract 1 being scripted dialogue and Extract 2 being 'real' interaction, the gendered dating theme is articulated similarly in both. Emma is trying to understand her boyfriend's behaviour, struggling to interpret his lack of communication: is he “jus' bein' oh: I'm a man”, and so acting in ways that have nothing to do with her own actions? Here, a description of the characteristics of a particular man, Emma's boyfriend (being 'casual'), is treated as typical of men in general, with the indefinite article in her formulation "I'm $a$ man" constructing the category. If her boyfriend is behaving like all men, then nothing of Emma's doing is prompting his actions.

In the absence of immediate uptake (line 10), Emma confirms her own categorization at line 11, then in light of a further lack of uptake, prefaces her next turn with 'or', a way of deleting the lack of response from recipients and turning her initial account into the first part of an 'either/or' formulation. This second candidate account for her boyfriend's 'casualness' is abandoned. At line 18, Sophie, sounding (in the audio recording) like she is in the midst of another activity, produces an affiliative response, giving Emma some advice, in which she takes Emma's descriptions and categorial formulation and upgrades them with the phrase "all men are bastards". She then spells out the upshot for 'you', which is hearable as a generic 'you' referring to the co-present friends as members of the contrast category 'women'. This upshot is that, "if you think the wo:rst then you can't get hu::rt.".

In Extract 2, then, the friends try to figure out the meaning of an absent party's actions - actions which appear similar to the sort of gendered dating behaviour discussed in Extract 1. Emma's boyfriend is treated as a member of a category rather than as an individual behaving in a situation-specific way, via her tying the category 'man' to the predicate 'casual'. Sophie offers a further gloss on his behaviour, as an instance of one member of the category 'men' being assessable as a 'bastard[s]'. Note that the phrase 'all men are bastards' is idiomatic: Not only are idioms commonly found in advice-giving (Hepburn \& Potter, 
2010), but categorial phrases, with their inbuilt generalizing quality, are regularly idiomatic or have an idiomatic quality. As Drew and Holt (1988: 501) have shown, idioms "have a special robustness which lends them the function of summarizing [an action] in such a way as to enhance its legitimacy". Both idioms and categorial formulations work as figurative, summarizing devices that are normatively 'correct about something' and hard to test empirically or challenge.

The next extract comes from the same data corpus as Extract 2, but here Sophie is describing problems with her own uncommunicative boyfriend.

\section{Extract 3: VH-1}

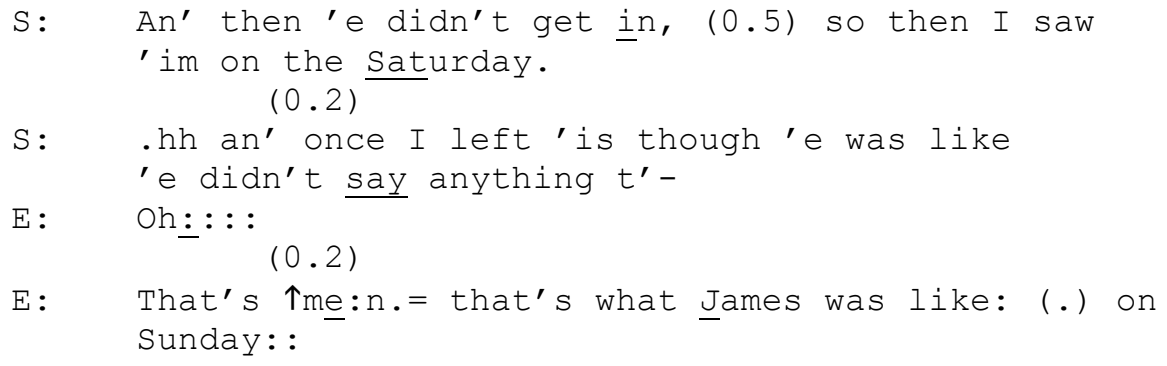

Sophie is listing the reasons why she has not seen much of her boyfriend: he "didn't get in [early enough to see her]", and he "'e didn't say anything to-". Although Sophie abandons what she was saying at the end of line 5 , it seems clear that what her boyfriend did not say anything about was making arrangements to meet. Emma demonstrates her understanding of this, and her empathy with Sophie: firstly in her response at line 6 (“Oh:.:.:”), and then in her proffered upshot of Sophie's account, in which she treats the described activities of Sophie's boyfriend as category-resonant; of typical of 'men in general' (“That's $\uparrow$ me:n."). The category encompasses a host of unspecified meanings of what 'men' are like. Emma then moves from the general category 'men' to describe an instance in her own boyfriend ("that's what James was like ..."), which both evidences the generalization and affiliates with her friend's complaint. 
Like previous extracts, we can see how participants move between description and categorization; treating each others' descriptions as category-resonant. Extract 4 comes from an internet 'community forum', on which forum members post and respond to problems of various kinds.

\section{Extract 4: www.handbag.com}

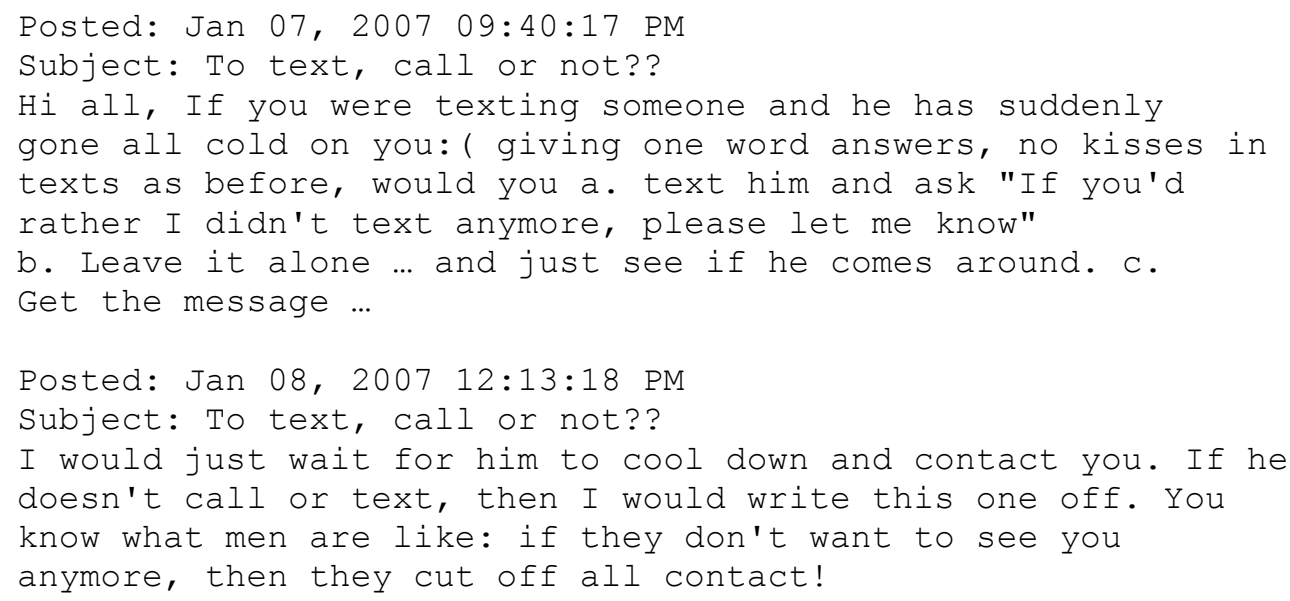

A similar pattern of problem-formulation and advice-giving can be observed in these textual materials. The first poster describes a problem in the texting behaviour of her current boyfriend; the second poster produces a category-based account for his actions ("You know what men are like"). Here, the parties formulate a range of activities (e.g., 'going cold', 'no kisses in texts', 'cutting off all contact') which poster 2 treats as category-resonant of the category 'men'.

Finally in this section, Extract 5 comes from a conversation between a group of student friends as they watch the television together in their shared house. Video stills show three women sitting on the sofa, who are addressing a fourth participant who is out of camera shot. 
Extract 5: JM-2

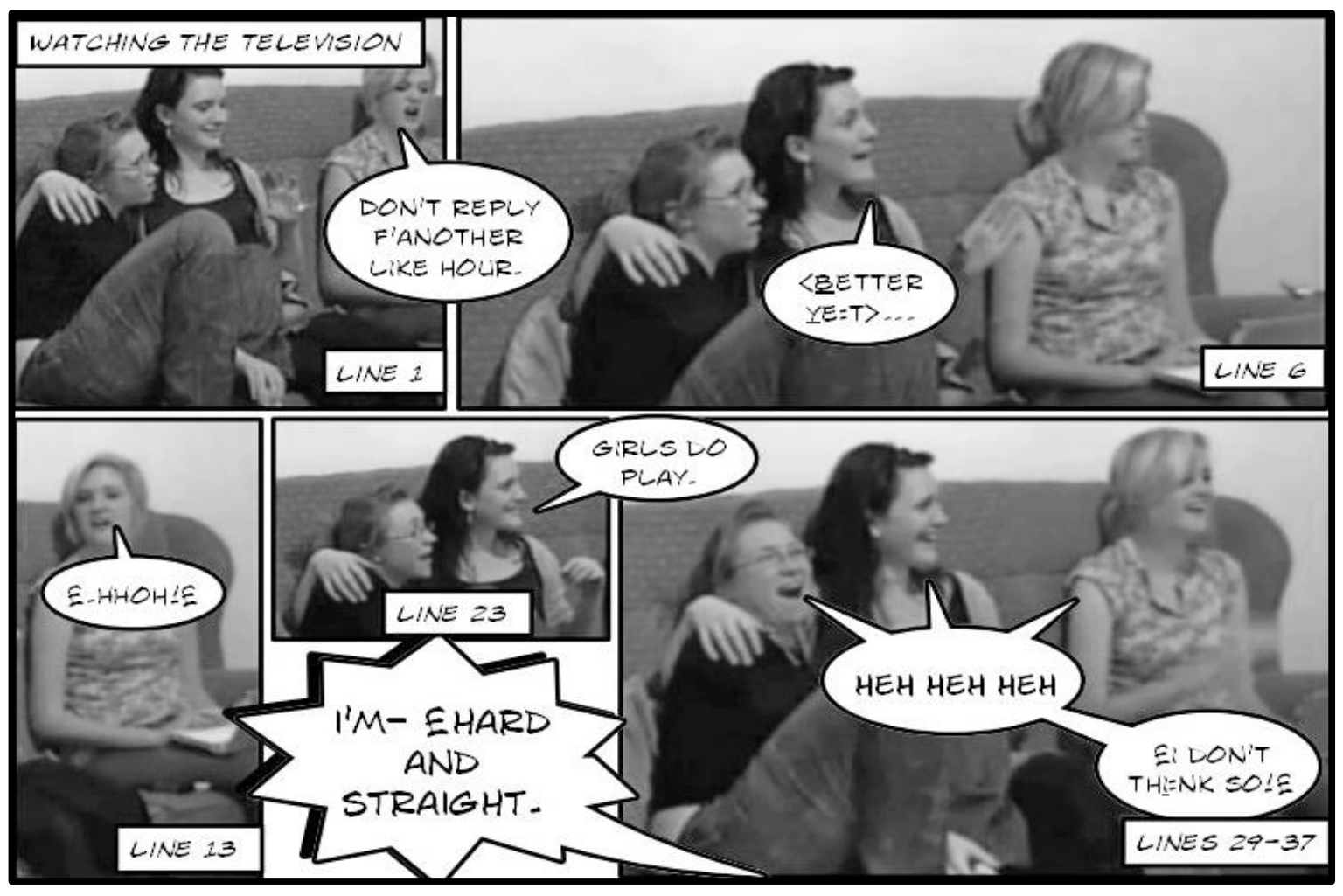

H: No: don't reply f'another like (.) [hour.

$\mathrm{S}:$ [At lea:st.

$(0.4)$

H: $\quad$ OOr in the [mornin',

...

C :

$[<$ Better ye: $t>$

(0.2) text 'er back in the mo:r[ning.

[Ye $[$ ah leave [it,

$S$

C :

[An' be

[Yeah.

like- I'm sorry I was out last ni:ght.

S: $\quad £ Y e a h ! £$

$\mathrm{H}: \quad £ . \mathrm{HHOh} ! £$

C: $\quad$ EThese are serious ga:mes. here:, [they =

G:

C:

$\mathrm{S}:$

$\mathrm{H}:$

$\mathrm{G}$ :

C :

G:

$\mathrm{C}:$

$\mathrm{S}:$

anywhere then-

$\mathrm{G}: \quad \mathrm{I} \mathrm{W}-\mathrm{I}-(\mathrm{)}$

$(0.2)$

C: Maybe th[is is £why we're alone.£]

G: $\quad\left[I^{\prime} m-\right.$ Łhard and straight.] $=[$ as a male. $£$

$S:$

[个This is-

=may feel like games but they're serious. $£$

play $\downarrow$ games. $=[(\uparrow)$

They $\uparrow$ don't ga: :me pl[ay,

[Girls do [play. Heh

[If you want to get

$$
(0.5)
$$

[个Shush. 


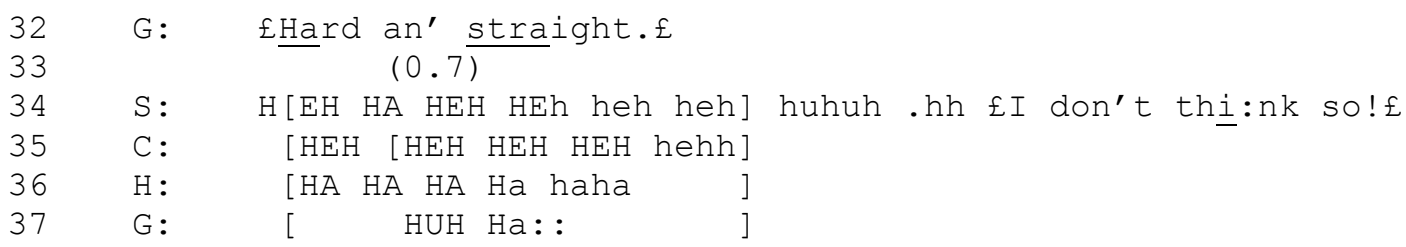

In this final dating advice-giving sequence, some friends are advising another on a course of action for his early dating activities with a new girlfriend. As in previous extracts, the activity of communicating with a new romantic partner, and, more specifically, the timing and pacing of such communication, is being discussed. In contrast to Extract 1, however, and to the tenor of the advice given in Extracts 2-4, the friends recommend slowing down the pace of replying to a text message $\mathrm{G}$ has received from his potential girlfriend: Between lines 1-2 $\mathrm{H}$ and $\mathrm{S}$ produce a turn and an increment which, together, recommend that G should not "reply f'another like (.) hour. At leâ:st.". H upgrades this suggestion to an even slower pace: "Orr in the mornin',", which is picked up and ratified by C (lines 6-7), which are further ratified by S and $\mathrm{H}$ (lines 8-9). C provides an additional component to this course of action: that $\mathrm{G}$ should tell his girlfriend that he was "out last ni:ght." (line 11). Again, S and $\mathrm{H}$ endorse this suggestion, smiling as they produce their approval for its disingenuous attributes.

The suggested course of activities are collected together and formulated by $\mathrm{C}$ as “serious ga:mes" (lines 14-16). At lines 19-20, however, $\mathrm{G}$ begins to resist the advice presented, saying that he "couldn't play $\uparrow$ games." G therefore claims, via the modal verb 'couldn't', a disposition not to be able to enact such a strategy (see Edwards, 2006). So whilst the advice-giving sequence has tied $\mathrm{H}, \mathrm{S}$ and $\mathrm{C}$ together as a collective of affiliating participants, in so doing they have become partitioned from G. Like Extract 1, the parties to this interaction are divided along gendered lines. The three women are tying together the activity of 'game-playing' (with various delaying and non-response strategies) to what "we do" (line 21). Here, 'we' is ambiguous, as a reference to 'we three co-present participants' or 'we as female'. Without specifying a gendered pronoun in his response, G rejects the notion 
that 'we play games', saying “They $\uparrow$ don't ga::me play," (line 22). While 'we' and 'they' are hearable as references to 'females in general', C replaces 'we' with 'girls' in her repair at line 23. Thus the gendering of the participants is observable not simply because of the perceptual availability of 'male' and female', but through this repair in which gender is specified as the MCD in play. In his response, G orients to the same MCD as he replaces a 'game-playing' strategy with being "£hard and straight.”, specifying this as a categorial strategy tied to being “a male.£” (lines 29, 32). The use of the indefinite article 'a' produces him as a representative member of the category. Thus both parties, while promoting diverging courses of action, are oriented to the same MCD.

In Extract 5, then, the female participants recommend that their male friend act in the same way that Chandler and his (male) friends were proposing to act (15 years earlier) in Extract 1, counter to his female friends' advice. In Extract 1, Monica and Phoebe recommended, effectively, a 'hard and straight' strategy for communicating with potential girlfriends. In Extracts 1-4, dating activities generalized to being typically male (not calling, not texting, delaying responding, not making firm arrangements, letting women dangle, etc.) were treated by the female participants as problematic for them as the 'female' recipients of such activities. In contrast, in Extract 5 the male participant resists acting in a typically male way. He ties different activities to being 'male', despite his female friends' attempts to perpetuate what other women see as typical, complainable, male dating behaviour. And the women, not the man, cast themselves as 'game players'.

Whilst the participants across these extracts invoke gender categories to proffer, account for and resist diverging courses of action, we can also see that what it means to be a typical 'male' or 'female' is not a permanent state of affairs. Proffered category-bound activities and predicates may be resisted; resisting such ties transforms the commonsense meanings of categories, and therefore such categorization work becomes central to social 
change (see Baker, 2000; Plunkett, 2009). As Clifton (2009: 3) points out, "categories do not reflect pre-discursive entities that are 'out there somewhere' and which members use to make sense of what is happening. Rather, what constitutes a category, and the predicates (i.e., expectable features, characteristics, behaviours, states of mind etc.) that accompany categories, are locally produced and are designed to 'do' social actions ... there is nothing a priori about the association of certain predicates with certain categories".

In the next section, I focus more closely on the movement between description of a local situation and a subsequent categorization, showing how such a practice regularly cooccurs with a particular component feature.

\section{(2) The anatomy of a categorial practice in account-giving}

In this section, another activity - account-giving - is the focus of systematic categorial analysis. As in the first section, we will focus on the way speakers invoke categories and generate category-bound features in the course of accomplishing a particular action, but attend particularly to the way categories coalesce with other components in and across turns, in accounts of various kinds. Once I began noticing this in one or two data extracts, I began to build a collection of instances across my various corpora and identified a robust categorial practice (see Stokoe, 2010b).

A key observation about the following collection of extracts is that Sacks's notions about the inference-rich nature of categories, introduced earlier, are built into the very categorial formulations themselves. It is not just that categories are, in theory and before empirical observation, 'inference rich', but that we can see that, and how, people treat categories as carrying inferential resources, in the design of their turns in which categorial formulations appear. And so, in contrast to 'wild and promiscuous' MCA, the inference-rich 
nature of categories is observable from the endogenous orientations of participants. I have examined such orientations in other practices, like self-repair. When speakers replace one category with another, they display an understanding that there are different ways of referring to women and that different categories carry different resonances and inferences. Category selection is therefore important not only for ensuring that the 'right' resonances and inferences are made relevant for the object of description, but also for the 'subject-side' (Edwards, 2005) inferences that can be made about the speaker as, say, 'gender aware' (e.g., "this girl then. $(.)^{\circ}$ that $^{\circ}$ this woman >sorry<") or as appropriately respectful (e.g., "the girl at the end- the lady at the end"). So category selection matters to people, even when a first term is referentially adequate and the replacement is its near synonym (Stokoe, 2011).

In the data that follow, the participants include a 'common knowledge component' (e.g., "you know?") as they build categorial turns, which proffers them as known-in-common, and as short-cutting, packaging devices that delete the need for further explanation and unpacking. Furthermore, as noted earlier, categorial phrases take on an idiomatic quality: they are one of Sacks's (1992: 8) “idiom-like things”. Phrases like 'all men are bastards' package and assert as common knowledge what people understand about particular category members. If a category-feature formulation 'works'; that is, it does not become the object of repair, then it works on the basis that speakers share category knowledge and unspecified inferences enough to progress the sequence underway.

Extract 6 comes from a radio broadcast in which the presenter (I) is interviewing a pharmacist $(\mathrm{Ph})$ about a scheme to sell Viagra directly to customers in high street chemists. Extract 7 comes towards the end of a telephone call between a member of the public (C) and a local council antisocial behaviour officer (A). C has complained about noise and aggressive behaviour from a neighbour and here she is providing an account for why it is that she cannot 
speak to him. Extract 8 comes from an online advice forum, in which the current poster is formulating a possible account for another poster's problematic boyfriend.

\section{Extract 6: BBC Radio 4 'Case Notes' 09-07}

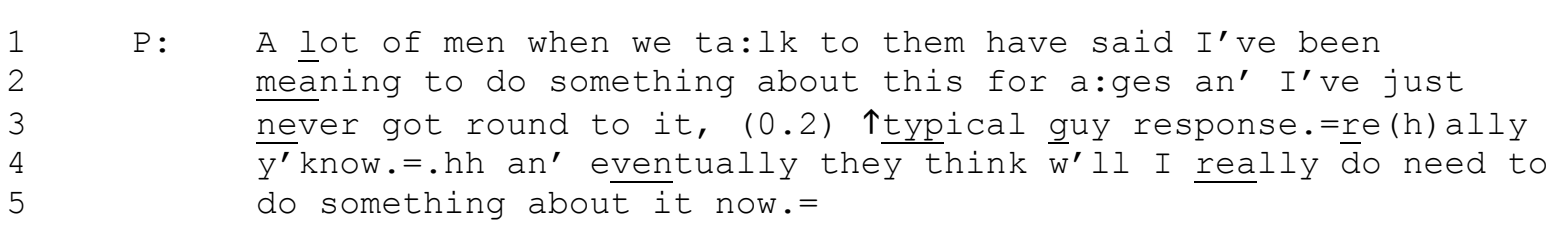

\section{Extract 7: AC-8}

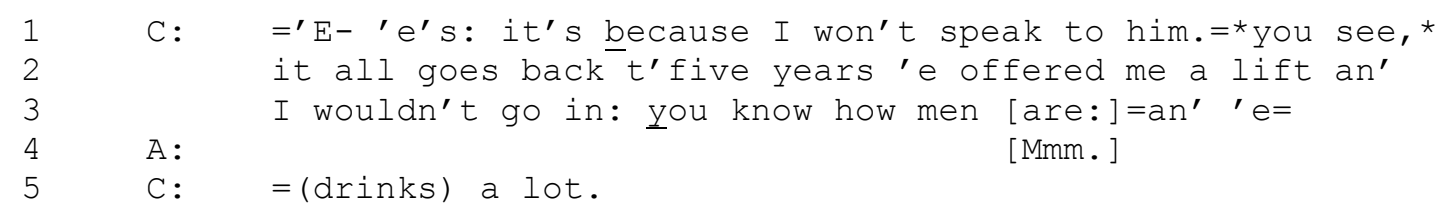

\section{Extract 8: http://uk.answers.yahoo.com}

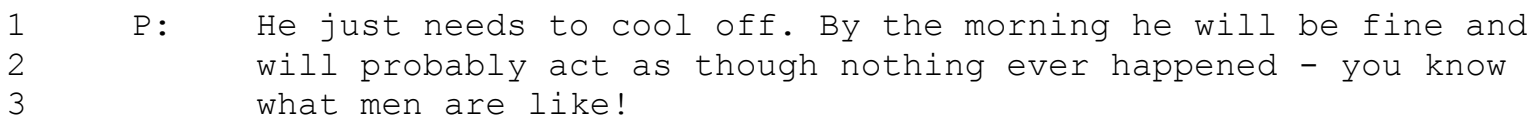

In Extract 6, the pharmacist is midway through answering a question about the sort of person that has been coming to her for Viagra. She describes an instance of the accounts given by "a lot of men" when they ask for Viagra, using the direct reported speech of individual men ("I've been meaning to do something about this", "I've just never got round to it"). The pharmacist then formulates a categorial upshot of her description: “个typical guy response." (line 3). In so doing, she proposes that the described activities of the individual men she encounters are typical of 'guys' in general. The notion that men are reluctant to go to the doctors, as a function of 'hegemonic masculinity', is well documented (e.g., Seymour-Smith, Wetherell \& Phoenix, 2002). However, using MCA allows us to nail down precisely phenomena that might otherwise be glossed as 'discourses', over-laden with theoretical 
baggage in a 'what-the-researcher-knows-first', rather than a 'what-the-participants-show-us' approach to analysis (see Stokoe, 2010a; Wooffitt, 2005).

Returning to Extract 6, “个typical guy response." ends the 'turn constructional unit' (TCU) that the pharmacist is currently formulating - note the falling pitch contour at the end of "response.". At this point, the turn is possibly complete and, as such, is at a 'transition relevance place' (TRP): the point at which a next speaker may legitimately start talking. However, the pharmacist rushes past the TRP to add a turn increment ("re(h)ally y'know."), keeping hold of the floor, and the interviewer does not make any response (she might have produced a 'continuer' such as “Mhm”). The turn increment comprises two words, the first of which is embedded with a laughter particle "re(h)ally" and the second is the common knowledge component in our categorial practice ("y'know."). By using these words, the pharmacist proposes to the recipient that her description and categorial upshot are recognizable and mutually shared, as part of the ongoing maintenance of a commonly shared, objectively existing world. The "re(h)ally" component, with its little laugh, also makes relevant the speakers' shared membership of the category 'women', who, by virtue of that membership also share cultural knowledge of a category's features (here, with an tongue-incheek stance, what men are typically like).

It is well-established that radio presenters and news interviewers generally display a neutral stance toward much of what their interviewees say (cf. Clayman \& Heritage, 2002; Hutchby, 2006). This may account for why the presenter does not display shared category knowledge at the point at which it might be relevant for her to do so. In Extract 7, however, there is some co-construction between speakers. At lines 1-3, C describes how she rejected an invitation from her neighbour and he responded badly ("it's because I won't speak to him.=*you see, ${ }^{*}=$ it all goes back t'five years 'e offered me a lift an' I wouldn't go in:"). C then moves from a description of the individual man's activities, to their formulation as 
categorial and common sense ("you know how men are:"). At line 4, in the midst of C's account, A produces a continuer, "Mmm” (see Gardner, 2002). Note its placement as C formulates the common knowledge component "you know". Here, then, is collaboration between speakers in terms of establishing some aspect of a man's behaviour as typical of men in general. Whilst this collaboration is fairly minimal (A's continuer aligns with C's general project of providing an account for her dispute, but does not affiliate or take a stance on it for example, “oh yes, I know!": see Stivers, 2008), what is important is that A does not initiate repair ("Huh?); the continuer is located precisely to display understanding of the particular category-based point $\mathrm{C}$ is making. Mutual category knowledge is foundational to the smooth progress of the activities under way.

Like Extract 6 ('个typical guy response.=re(h)ally y’know.’), “'you know how men are:" has an idiomatic quality, packaging and shortcutting commonsense knowledge that the speakers, as members of the identity category 'women', will share. What is this shared knowledge? There are infinite, defeasible, versions. It is something like the notion that men initiate and are the agents of romantic encounters, with women being in the position of saying 'no' and establishing the boundaries of such encounters (see Kitzinger \& Frith, 1999; Wowk, 1984). But the inferences of the category are not further specified (such that analysts can assert them!): the categorial formulation short-cuts any further explanation as common ground is proffered and accepted. For the participants, however, there is enough shared category knowledge about 'how men are' for the conversation to continue.

In Extract 8, the same component features can be observed in written text. The online poster describes the possible activities of a particular man ('cooling off'; 'acting fine in the morning'), accounts for them as typical of the category 'men' in general, and constructs this categorial knowledge as shared (“you know what men are like!”). In this online environment, there are limited possibilities for producing the sorts of 'continuer' turns we observed in 
Extract 7, and subsequent responses from original posters tend to orient to the action of the posts (“thanks for all your advice!"). Nevertheless, such materials provide further evidence for the robustness of this categorial practice, in which three coalescing components work together to formulate an idiom or idiomatic-sounding phrase (e.g., "typical guy response really, you know"; "you know how men are"; “you know what men are like!").

Here are a further three examples, each of which come from police interrogations of suspects. In Extract 9, the suspect has been arrested on suspicion of breaching a 'second harassment warning' regarding his neighbour, with whom he had a brief romantic relationship. $\mathrm{S}$ is accused of repeatedly knocking on her door and various other ways of trying to make contact with her. In Extract $10, \mathrm{~S}$ is accounting for his involvement in an affray with his neighbour. And in Extract 11, S has admitted criminal damage to her neighbour's door and is currently providing an account of some mitigating circumstances.

\section{Extract 9: PN-27}

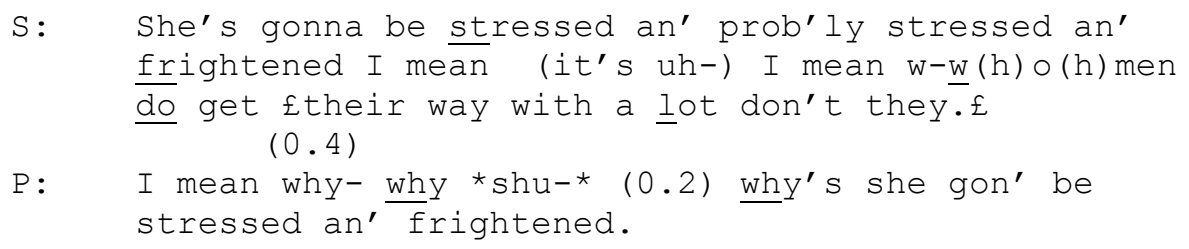

\section{Extract 10: PN-48}

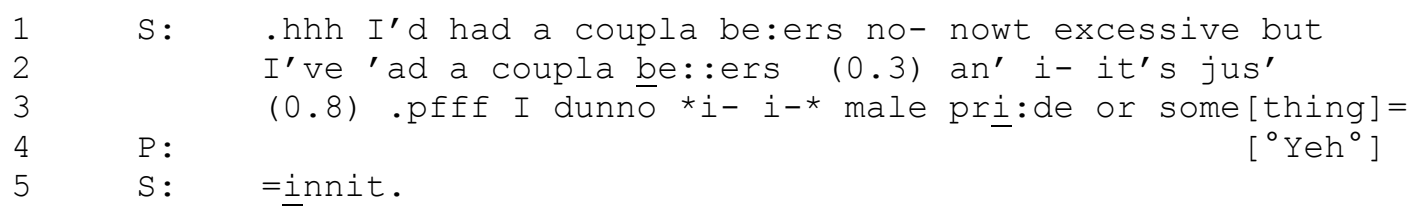

\section{Extract 11: PN-4}

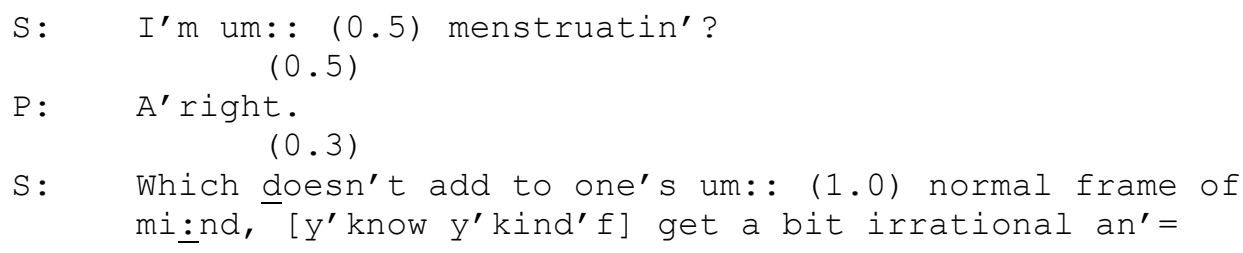




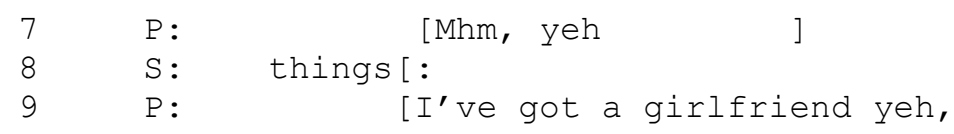

Prior to the start of Extract 9, whether S's actions are categorizable as 'harassment' or 'ordinary neighbourly behaviour' has occupied much of the interview. S is currently answering P's question about how Karen "felt" about his actions. S moves between describing her particular feelings (“she's gonna be stressed an' prob'ly stressed an' frightened") and categorizing her feelings as typical of women in general ("I mean w$\underline{\mathrm{w}}(\mathrm{h}) \mathrm{o}(\mathrm{h}) \mathrm{men} \underline{\mathrm{do}}$ get their way with a lot"): Karen's particular behaviour is not responsive to anything S has done, but results from her membership of the category 'women'. He appeals directly to P to display shared category knowledge via the common knowledge component at the end of his turn via a tag question, “don't they.£”. Note that, like Extract 6, S's pursuit of a response from his recipient is delivered with smiley-voice (the category “w $\underline{w}(\mathrm{~h}) \mathrm{o}(\mathrm{h}) \mathrm{men}$ ” also contains interpolated laughter) and, like Extract 7, makes relevant the co-present parties' shared membership of the opposite gender category; this time, 'heterosexual men', who know what 'women' are like.

$\mathrm{P}$ does not respond to S's question with the preferred second pair part in a questionanswer adjacency pair of turns. One reason for this is that a 'type-conforming' response to S's 'yes-no interrogative' question (e.g., "Yes [they do]" or "no [they don’t]") would necessarily display P's stance towards ‘what women get away with' (see Raymond, 2003). As I have shown elsewhere, police officers normatively resist answering these sorts of questions from suspects, as part of a strategy of avoiding self-disclosure more generally (Stokoe, 2009b). Not only would answering S's question alter the identity relevancies of the speakers, from 'officer-suspect' to 'man-man', it would ratify the suspect's account as it is built as evidence. So while S pursues an affiliative, 'co-member' response from P, P's lack of response tells us something about the 'rules' of this encounter in which he maintains a neutral 
stance towards what S says and does not take up the offer of shared category memberships. Instead, P's delayed response does not respond to the question, and does not affiliate with S, but turns S's description of Karen's feelings into a counter question about why she is stressed and frightened, ignoring the categorial components of S's turn.

In Extract 10, $\mathrm{S}$ is providing an account for why he engaged in a fight with a neighbour rather than walk away. S supplies a category-based response following description of his individual behaviour ("I'd had a coupla be:ers") His answer treats the activity of 'walking off' as not tied to the category 'male'; that is, that 'proud' males do not walk away from a fight. In so doing, S implies that his actions were justified by virtue of 'male' category incumbency. The common knowledge component is attached to the categorization ("innit."), following which $\mathrm{P}$ produces a minimal alignment token at line 4. Indeed, on this occasion, P's "oYeh"” (line 9) occurs before S's direct appeal for ratification in his tag-formatted common knowledge component (line 5).

Finally, in Extract 11, the analytic interest is what happens at line 9. Until this point, $\mathrm{P}$ has been offering continuers throughout S's narrative account (e.g., line 3, 7). As we have seen in Extract 7, police officers do not generally join in with suspects' appeals to display shared category knowledge, or occupy shared category memberships. However, following S's

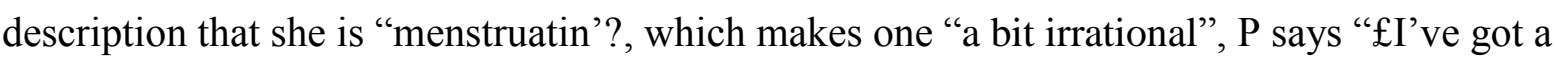
girlfriend yeah,£'. Thus P treats S's descriptions as recognizable activities for 'girlfriends': as category-resonant or category-implicative. Note that P says "I've got $a$ girlfriend", rather than something like "my girlfriend's like that", using the indefinite article 'a' to construct something as categorial and general: 'girlfriends' do irrational things when menstruating. The common knowledge component is delivered by $\mathrm{S}$ at line 6 (“y'know"), as she talks more generally about the effects of menstruation on 'one'. P does a continuer at this point (line 7), making his categorization at line 9 something of an 'upgraded', volunteered' response: a rare 
example of 'self-disclosure' which also proffers temporary alternative category memberships to the 'suspect' and 'police officer' as 'heterosexual' males and females.

In this section, I have shown how categorial formulations follow descriptions of individual activities or events; that speakers treat their own or each others' descriptions as category-resonant or category-bound and, via a common knowledge component, propose that knowledge of such categories is shared, or pursued as shared. This categorial practice occurred within a particular action-oriented environment: account-giving. In addition to the regular way in which category-activity pairs co-occurred in the advice-giving sequences examined in the first analytic section, we can begin to see how categorial phenomena fall out into patterns more readily than one might intuit. The final analytic section focuses on the basic unit of sequence construction in CA, the adjacency pair (Schegloff, 2007b), and a familiar type of paired actions: the question-answer.

\section{(3) Going categorial in question-answer sequences}

This final section addresses a fundamental CA phenomenon which has been researched extensively across numerous domestic and institutional contexts: the question-answer adjacency pair (for a recent review and collection of studies, see Freed \& Ehrlich, 2010). Within this extensive body of work, however, little if any attention has been paid to categorial responses to questions and their function. It is one thing that people can do when answering a question about a specific thing, to generalize or go categorial in response.

In Extract 12, we return to the radio interview with the pharmacist we encountered earlier. This question-answer pair occurs just before Extract 6 . 


\section{Extract 12: BBC Radio 4 'Case Notes' 09-07}

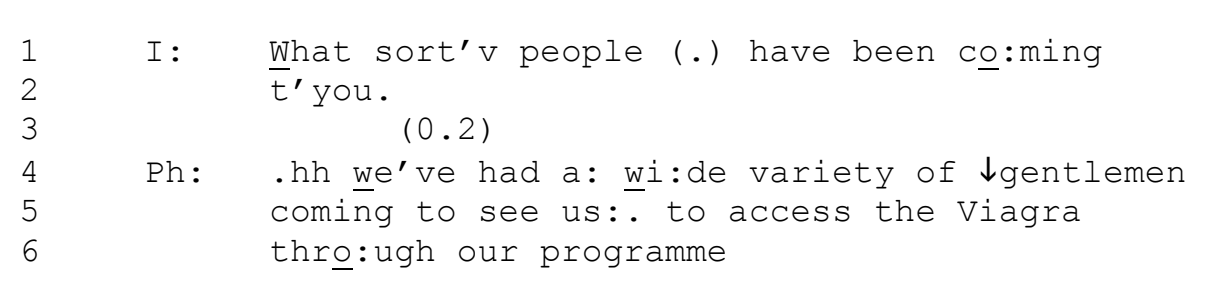

In this first extract, the interviewer's question makes relevant a categorial answer, asking about the "sort'v people" that have visited the pharmacist. Thus the 'first pair part' of this 'question-answer' adjacency pair generates a category-relevant environment and, indeed, the pharmacist responds in categorial terms: “a: wii:de variety of $\downarrow$ gentlemen” have visited her pharmacy. Thus, the pharmacist's preferred response is fitted to the 'wh-' question that initiates the sequence.

However, in the following extract, from a conversation between two people on a 'speed-date', a categorial answer is produced in response to a 'wh-' question that makes relevant an account, but not necessarily a category-based account.

\section{Extract 13: SD-7}

$\begin{array}{lll}1 & F: & {[\ldots] \text { Why Leicester then. }} \\ 2 & M: & \text { Why } \uparrow \text { Leicester: : I followed a wo :man. }\end{array}$

In response to a 'wh-' question about why M moved from Stratford-upon-Avon to Leicester, M produces an answer which contains a categorial account for his actions: "I followed a wo:man.". This account generalizes his actions and embeds them in a culturally familiar plot. This 'cultural familiarity' is built into the grammar of the turn, in that M talks about following 'a' woman, rather that specifying a particular woman; a category-based reason for doing something. Similarly, in Extract 14 below (which comes from the same police interview we saw in Extract 10), a suspect supplies a category-based answer to a 'wh-' question. 


\section{Extract 14: PN-48}

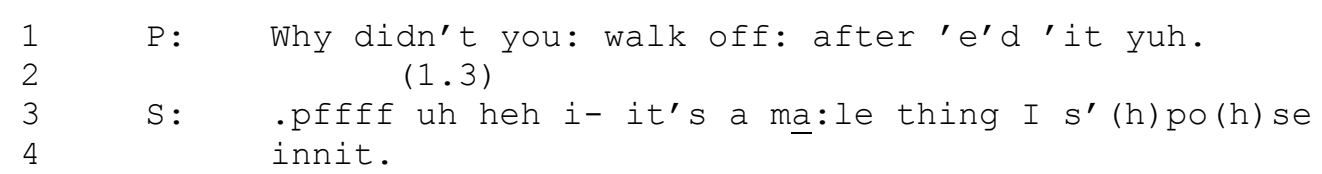

Like Extract 13, the question that initiates the sequence prefers a descriptive, but not necessarily categorial, account. However, S supplies a category-based response: that he did not 'walk off' when his neighbour hit him because "it's a ma:le thing”. As we saw in Extract $10, \mathrm{~S}$ 's answer treats the activity of 'walking off' from a fight as problematic for a member of the category 'male'. In so doing, $\mathrm{S}$ implies that his actions were justified by virtue of 'male' category incumbency.

In Extracts 15-17, a particular sequential pattern can be observed in the way suspects in police interrogations supply category-based accounts after type-conforming answers to questions. In each case, the suspect has been arrested on an assault charge (for an extended treatment of these and similar extracts, see Stokoe, 2010a).

\section{Extract 15: PN-63}

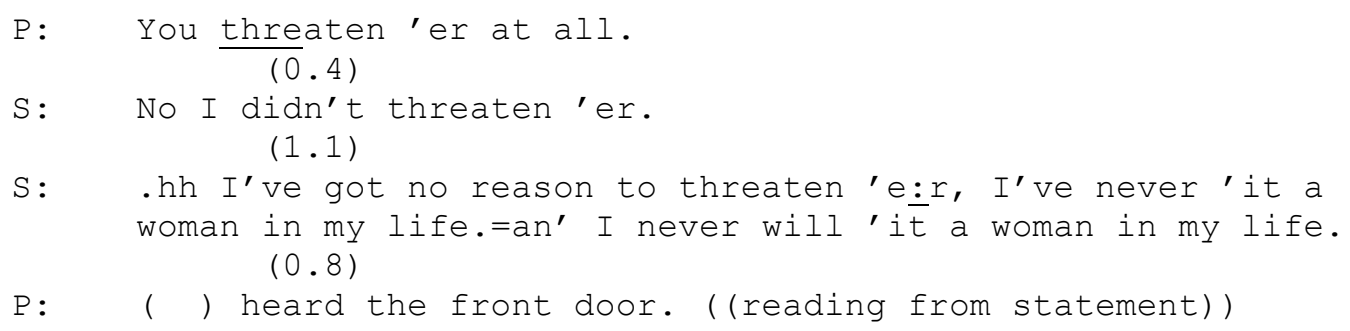

\section{Extract 16: PN-111b}

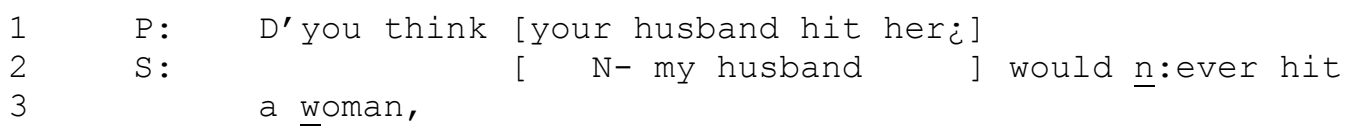

\section{Extract 17: PN-61} $\begin{array}{lll}1 & \text { P1: } & D^{\prime} y^{\prime} \text { member 'er falling down to the gro:und, } \\ 2 & \text { S: } & \text {.hhhhhhhh }\end{array}$ 


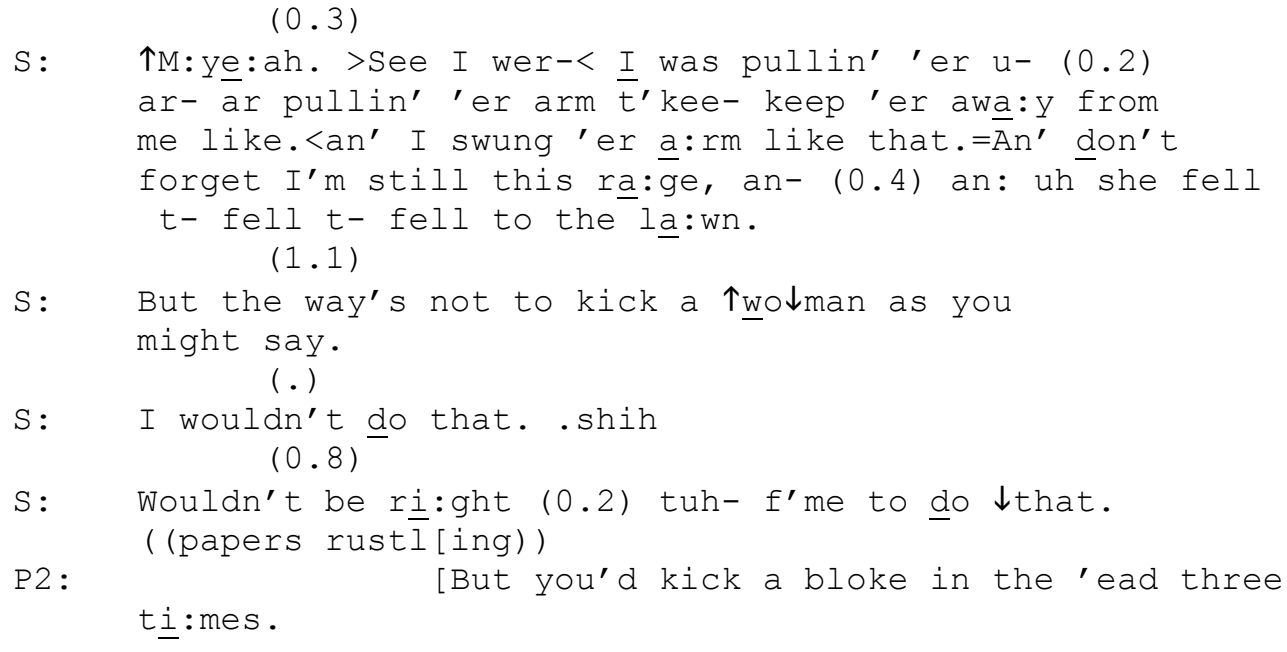

In each instance, suspects are denying the actions they are accused of, or, in the case of Extract 16, that their partner is accused of. The questions are formatted grammatically as 'yes/no interrogatives' about a specific person or incident. Suspects respond with a typeconforming response ('yes' or 'no') but then follow up with an account in which they supply a category-based denial (Stokoe, 2009a) in a 'post-expansion' slot. That is, the suspects expand the basic first and second pair part adjacency pair of turns to 'go categorial'.

In Extract 15, P asks S whether or not he 'threatened' the alleged assault victim. S first answers the question with a denial (line 3) and then provides an account (lines 5-6). While P's question is about a particular person, S's response moves from the particular to the general via categorization S's account is built as three items in a list, the first of which attends to the police-relevant issue of 'motive' and addresses the woman in question ("I've got no reason to threaten 'e:r,"). The second item, "I've never 'it a woman in my life.", addresses a generalized category (“a woman"). The third item ("I never will 'it a woman") includes the modal term 'will' (of which 'would' is a past tense form). Edwards (2006: 475) has shown how, when denying a charge put to them, suspects may use such modalized declaratives to "claim a disposition to act in ways inconsistent with whatever offence they are accused of'. Here, because S would not in general do the action he is charged with, he did not do it this time. Taken together, items two and three categorize $\mathrm{S}$ as the kind of man who, 
as a part of his disposition or character, does not 'hit women' in general. This is because the 'I' is an instance of what Jackson (2011) calls a 'gendered I', a self-referential pronoun which "can be rendered hearably gendered in the context of its production".

Note that P does not respond to S's self-categorization as the type of man who does not hit women (line 7); that is, he neither accepts nor rejects it as a piece of evidence but instead launches a new sequence about further witness testimony. But neither does P display any trouble in recognizing the account by, say, initiating repair. The recognizability of his account rests on shared knowledge of S's pairing of a category with an activity: that 'men' may 'hit women'. So S simultaneously recruits the culturally familiar notion that men perpetrate violence towards women (that is, there are gender-specific slots that map onto the categories 'perpetrator' and 'victim', see Lee, 1984), and uses it to deny that he is such a man, taking up a moral stance against 'men who hit women'.

The same pattern can be observed in Extracts 16 and 17. Having denied that she hit the alleged assault victim, in Extract $16 \mathrm{P}$ asks about the possible involvement of S's husband. S's account, like the suspect's account in Extract 15, constructs a recognizable category-activity combination (that of 'men' + 'hitting' + 'women'), but uses it to deny that her husband hit their neighbour because he is the kind of man who "would $\underline{n}$ :ever hit a woman,". Similarly, in Extract 17, the suspect produces an account for his type-confirming denial: "But the way's not to kick a $\Upsilon_{\underline{w o}} \downarrow$ man as you might say. (.) I wouldn’t $\uparrow \underline{\text { do }}$ tha:at.”. S moves away from a general, scripted claim ("the way's ...", cf. Edwards, 1994) to a specific one (“I wouldn’t...”), pairing "wouldn't" with a generalized formulation of the gender category "a $\uparrow \underline{w o} \downarrow$ man", rather than the particular woman he is accused of kicking. S then reiterates his denial: “Wouldn’t be rị:ght. (0.2) to: f'me to do $\downarrow$ that.” In his follow-up question, P2 invokes S's denial: "But you'd kick a bloke in the 'ead three ti:mes", which S does not challenge. Note that $\mathrm{P}$ also uses a generalized gender category "a bloke" here, that 
orients to "a woman" as a member of a contrastive relational pair: both S and $\mathrm{P}$ are therefore oriented to the same membership categorization device.

Here, then, S admits assaulting another 'man', but denies assaulting a 'woman', making his own gender identity relevant. Such a denial works on the basis that assaulting members of equivalent categories - with regards to power, physical strength, and vulnerability - is a more morally acceptable action than assaulting members of relatively 'weaker' categories (see Stokoe, 2009a, on 'young' suspects' denials of assaulting 'old' people). In other words, S constructs 'man' and 'woman' as positioned categories. Note the way S's denial is built: it starts with "But the way's" and ends with "as you might say". These parts of the turn work to formulate the middle bit, "not to kick a $\underline{\text { wo }} \downarrow$ man" as commonsense and idiomatic, and, as such, reality-constructing with regards to the asymmetrical organization of a culture's categories: there are hittable men and unhittable women; men who do and do not hit women. In this sense, then, MCA offers not just a commentary on the sequential structures of, here, police interrogation, but an insight into 'culture-in-action' (Hester \& Eglin, 1997).

\section{MOVING FORWARD WITH MEMBERSHIP CATEGORIZATION ANALYSIS}

This paper has attempted to accomplish four things. First, it has considered the hierarchical relationship between conversation analysis (CA) and membership categorization analysis (MCA). In so doing, it will hopefully prompt fresh - and not simply caricatured or disengaged - debate about the relationship between these two lines of ethnomethodological inquiry, in ways that that will be productive for both. I suggested at the beginning of the article that CA is the 'juggernaut' to MCA's 'milk float', and that for MCA to survive either as a separate discipline, or as an equivalent focus within $\mathrm{CA}$, it must generate new types of 
systematic studies that reveal fundamental discourse practices. With such a goal in mind, the second accomplishment of the paper has been to provide a set of clear analytic principles, 'keys' and procedures for conducting MCA, which are grounded in basic categorial and sequential concerns. Third, the empirical examples have demonstrated how order can be found in the intuitively 'messy' discourse phenomenon of membership categories, and how to approach their analysis systematically such that they may be studied as a robust feature of particular action-oriented environments. Crucially, target categories did not start out as (my) analysts' categories: I did not use 'gender' to explain the presence of particular actions, nor make tenuous assertions about the relevant activities and predicates that are bound to it. Nevertheless, and finally, I hope that the exemplar analyses have shown how MCA can tell us something about 'the commonsense routine workings of society' (Fitzgerald et al, 2009) without adopting a 'wild and promiscuous' analytic approach - even if being 'wild and promiscuous' sounds rather more interesting than being 'tame and chaste'...

Across the different analytic sections, we have seen how speakers invoke, produce, sustain and resist a category's situated meanings. We can see 'what counts', in my examples, as gendered attributes and actions (e.g., making the first move on a date, being casual in relationships, being reluctant to go to the doctors, letting women dangle, not hitting women, and so on). As categories come interactionally and textually into view, they are given a takenfor-granted and enduring veracity. It is through categorization practices that "the world is rendered objectively available and is maintained as such" (Heritage, 1984: 220; see also Lynch, 1993).

As I have suggested elsewhere (Stokoe, 2010a), MCA can give us what a macro-level analysis of discourses does not: a warrantable method for making claims about "the world" and its categorial arrangements (Fitzgerald et al, 2009: 47; see also Wooffitt, 2005). Baker (2000: 112) has argued that the analysis of categories shows how 'discourses', if one finds 
the concept appealing, are "locked into place". She writes that, "When speakers 'do describing', they assemble a social world in which their categories have a central place ... these are powerful statements about what could be the case, how the social order might be arranged, whether or not it really is" (Baker, 2004: 175). I have suggested that, not 'by their nature' but in their empirical use, categories short-cut and package common sense knowledge about category members and their actions. That is, by building into categorial formulations devices for saying 'there-is-more-to-this-category-than-I-need to-describe-here' (a 'common knowledge component'; an idiomatic quality), and by observing that such formulations are often collaboratively built between parties, the 'inference-rich nature of categories' is, in fact, an endogenous orientation of those parties. Building large, multi-modal and multi-setting datasets enables this type of corpus-based MCA. Furthermore, juxtaposing data extracts from disparate settings that nevertheless contain the same description - category - predicateaction combinations (e.g., gendered actions in early dating advice; gendered orientations in questions about violence) builds our understanding of the world, society and its categories. Overall, then, I hope this paper provides a framework of procedures for and examples of MCA for debate and a new generation of studies of the categories of our everyday domestic, institutional and virtual lives. 


\section{NOTES}

1. At least in its 'pure' form; 'applied' or 'institutional' CA conducts studies in discrete settings. But this distinction, and orientation to materials, is not without controversy (see Benwell \& Stokoe, 2006).

2. Much of the data were collected as part of ESRC grant number RES-148-25-0010 "Identities in neighbour discourse: Community, conflict and exclusion" held by Elizabeth Stokoe and Derek Edwards.

3. I would like to thank Eric Laurier for introducing me to 'Comic Life' software.

\section{ACKNOWLEDGEMENTS}

I would like to thank Frederick Attenborough, Derek Edwards, Joanne Meredith, Jonathan Potter and Emma Richardson for their comments on earlier drafts of this paper. 


\section{REFERENCES}

Antaki, C., \& Widdicombe, S. (Eds.) (1998). Identities in talk. London: Sage.

Baker, C.D. (2000). Locating culture in action: Membership categorization in texts and talk. In A. Lee \& C. Poynton (Eds.), Culture and text: Discourse and methodology in social research and cultural studies (pp. 99-113). London: Routledge.

Baker, C.D. (2004). Membership categorization and interview accounts. In D. Silverman (Ed.), Qualitative research: Theory, method and practice (Second edition, pp. 162176). London: Sage.

Benwell, B.M., \& Stokoe, E. (2006). Discourse and identity. Edinburgh: Edinburgh University Press.

Carlin, A. (2010). Reading ‘A tutorial on membership categorization' by Emanuel Schegloff. Journal of Pragmatics, 42, 257-261.

Chomsky, N. (1957). Syntactic structures. The Hague: Mouton de Gruyter.

Clayman, S., \& Heritage, J. (2002). The news interview: Journalists and public figures on the air. Cambridge: Cambridge University Press.

Clifton, J. (2009). A membership categorization analysis of the Waco Siege: Perpetratorvictim identity as a moral discrepancy device for 'doing' subversion. Sociological Research Online, 14 (5) 8. <http://www.socresonline.org.uk/14/5/8.html>

Drew, P., \& Holt, E. (1988). Complainable matters: The use of idiomatic expressions in making complaints. Social Problems, 35 (4), 501-520.

Edwards, D. (2006). Facts, norms and dispositions: Practical uses of the modal would in police interrogations. Discourse Studies, 8 (4), 475-501.

Edwards, D. (2005). Moaning, whinging and laughing: The subjective side of complaints. Discourse Studies, 7 (1), 5-29. 
Edwards, D. (1998). The relevant thing about her: Social identity categories in use. In C. Antaki \& S. Widdicombe (Eds.), Identities in talk. London: Sage.

Edwards, D. (1994). Script formulations: A study of event descriptions in conversation. Journal of Language and Social Psychology, 13 (3), 211-247

Eglin, P., \& Hester, S. (1999). "You're all a bunch of feminists!": Categorization and the politics of terror in the Montreal Massacre. Human Studies, 22, 253-272.

Fitzgerald, R., Housley, W., \& Butler, C. (2009). Omnirelevance and interactional context. Australian Journal of Communication, 36 (3), 45-64.

Freed, A.F., \& Ehrlich, S. (Eds.) (2010). Why do you ask? ": The function of questions in institutional discourse. Oxford: Oxford University Press.

Gardner, R. (2002). When listeners talk: Response tokens and recipient stance with special reference to 'Mm'. Amsterdam: Benjamins.

Goodwin, C. (2003). Recognizing assessable names. In Studies in Language and Social Interaction: In Honour of Robert Hopper, P. Glenn, C.D. LeBaron and J. Mandelbaum (eds.), 151-162. Mahwah, NJ: Lawrence Erlbaum Associates.

Hansen, A.D. (2005). A practical task: Ethnicity as a resource in social interaction. Research on Language and Social Interaction, 38 (1), 63-104.

Heritage, J. (2005). Conversation analysis and institutional talk. In K.L. Fitch \& R.E. Sanders (Eds.), Handbook of Language and Social Interaction. Mahwah, NJ: Lawrence Erlbaum

Heritage, J. (1984). Garfinkel and ethnomethodology. Cambridge: Polity.

Hepburn, A., \& Potter, J. (2010). Interrogating tears: Some uses of 'tag questions' in a child protection helpline. In A.F. Freed \& S. Ehrlich (Eds.). Why do you ask?": The function of questions in institutional discourse. Oxford: Oxford University Press. 
Hester, S., \& Eglin, P. (Eds.) (1997). Culture in action: Studies in membership categorization analysis. Boston, MA: International Institute for Ethnomethodology and University Press of America.

Hester, S., \& Francis, D., (1997). Reality analysis in a classroom storytelling. British Journal of Sociology, 48, 1, 95-112.

Housley, W., \& Fitzgerald, R. (2009). Membership categorization, culture and norms in action. Discourse \& Society, 20 (3), 345-362.

Housley, W., \& Fitzgerald, R. (2007). Categorization, interaction, policy, and debate. Critical Discourse Studies, 4 (2), 187-206.

Hutchby, I. (2006). Media talk: Conversation analysis and the study of broadcasting. Glasgow: Open University Press.

Jackson, C. (2011). The gendered 'I'. In Speer \& E. Stokoe (Eds.), Conversation and gender. Cambridge: Cambridge University Press.

Jayyusi, L. (1984). Categorization and the moral order. London: Routledge.

Jayyusi, L. (1991). Values and moral judgement: Communicative praxis as a moral order. In G. Button (Ed.), Ethnomethodology and the human sciences. Cambridge: Cambridge University Press.

Jefferson, G. (2004). Glossary of transcript symbols with an introduction. In Conversation Analysis: Studies From the First Generation, G. Lerner (ed.), 13-31. Amsterdam: John Benjamins.

Kitzinger, C., \& Frith, H. (1999). Just say no? The use of conversation analysis in developing a feminist perspective on sexual refusal. Discourse \& Society, 10 (3), 293-316.

Lee, J. (1984). Innocent victims and evil-doers. Women's Studies International Forum, 7 (1), $69-73$.

Lepper, G. (2000). Categories in text and talk. London: Sage. 
Lynch, M. (1993). Scientific practice and ordinary action: Ethnomethodology and social studies of science. Cambridge: Cambridge University Press.

Plunkett, R. (2009). Fashioning the feasible: Categorization and social change. Australian Journal of Communication, 36 (3), 23-44.

Pomerantz, A., \& Mandelbaum, J. (2005). Conversation analytic approaches to the relevance and uses of relationship categories in interaction. In K.L. Fitch \& R.E. Sanders (Eds.), Handbook of language and social interaction. Mahwah, NJ: Lawrence Erlbaum Associates.

Raymond, G. (2003). Grammar and social organization: Yes/No interrogatives and the structure of responding. American Sociological Review, 68, 939-967.

Raymond, G., \& Heritage, J. (2006). The epistemics of social relationships: Owning Grandchildren. Language in Society, 35 (5), 677-705

Sacks, H. (1992). Lectures on conversation (vols. I and II, edited by G. Jefferson). Blackwell, Oxford.

Sacks, H. (1979). A revolutionary category: Hotrodder. In G. Psathas (Ed.), Everyday language: Studies in ethnomethodology (pp. 7-14). New York: Irvington.

Schegloff, E.A. (2007a). A tutorial on membership categorization. Journal of Pragmatics, 39, $462-482$.

Schegloff, E.A. (2007b). Sequence organization in interaction: A primer in conversation analysis. Cambridge: Cambridge University Press.

Schegloff, E.A. (2005). On integrity in inquiry... of the investigated, not the investigator. Discourse Studies, 7 (4-5), 455-480.

Schegloff, E.A. (1992). Introduction to Sacks 'Lectures on Conversation' Volume 1. In H. Sacks, Lectures on conversation (vols. I and II, edited by G. Jefferson). Blackwell, Oxford. 
Schegloff, E.A. (1991). Reflections on talk and social structure. In D. Boden \& D. Zimmerman (Eds.), Talk and social structure. Berkeley, CA: University of California Press.

Seymour-Smith, S., Wetherell, M., \& Phoenix, A. (2002). "My wife ordered me to come!": A discursive analysis of doctors' and nurses' accounts of men's use of general practitioners. Journal of Health Psychology, 7 (3), 253-267.

Sidnell, J. (2010). Conversation analysis: An introduction. Oxford: Blackwell-Wiley.

Silverman, D. (2001). Interpreting qualitative data: Methods for analysing talk, text and interaction. London: Sage.

Silverman, D. (1998). Harvey Sacks: Social science and conversation analysis. Cambridge: Polity Press.

Speer, S.A., \& Stokoe, E. (2011). Conversation and gender. Cambridge: Cambridge University Press.

Stokoe, E. (2011). "Girl - woman - sorry!”: On the repair and non-repair of consecutive gender categories. In S. Speer \& E. Stokoe (Eds.), Conversation and gender. Cambridge: Cambridge University Press.

Stokoe, E. (2010a). "I'm not gonna hit a lady": Conversation analysis, membership categorization and men's denials of violence towards women. Discourse \& Society, 21(1), 1-24.

Stokoe, E. (2010b). Gender, conversation analysis, and the anatomy of membership categorization practices. Social and Personality Psychology Compass, 1-12, 10.1111/j.1751-9004.2010.00261.x

Stokoe, E. (2009a). Doing actions with identity categories: Complaints and denials in neighbour disputes. Text and Talk, 29 (1), 75-97. 
Stokoe, E. (2009b). "I've got a girlfriend": Police officers doing 'self-disclosure' in their interrogations of suspects. Narrative Inquiry, 19 (1), 154-182.

Stokoe, E.H. (1998). Talking about gender: The conversational construction of gender categories in academic discourse. Discourse \& Society, 9 (2), 217-240.

Stivers, T. (2008). Stance, alignment, and affiliation during storytelling: When nodding is a token of affiliation. Research on Language and Social Interaction, 41 (1), 31-57.

Summerfield, T., \& McHoul, A. (2005). Family as a commonsensical device and its lace in law. International Journal for the Semiotics of Law, 18, 243-261.

Van Dijk, T. (1987). Communicating Racism: Ethnic Prejudice in Thought and Talk. London: Sage.

Watson, D.R. (1997). Some general reflections on 'categorization' and 'sequence' in the analysis of conversation. In S. Hester \& P. Eglin (Eds.) (1997). Culture in action: Studies in membership categorization analysis (pp. 49-75). Washington, DC: University Press of America.

Watson, D.R. (1978). Categorization, authorization and blame-negotiation in conversation. Sociology 12 (1): 105-113.

Whitehead, K.A. (2009). "Categorizing the categorizer”: The management of racial common sense in interaction. Social Psychology Quarterly, 72 (4), 325-342.

Wilkinson, S., \& Kitzinger, C. (2008). Using conversation analysis in feminist and critical research. Social and Personality Psychology Compass, 2 (2), 555-573.

Wooffitt, R. (2005). Conversation analysis and discourse analysis: A comparative and critical introduction. London: Sage.

Wowk, M.T. (1984). Blame allocation, sex and gender in a murder interrogation. Women's Studies International Forum, 7, 75-82. 